\title{
Influence of acute haemodynamic changes on the oxygen saturation during electro-convulsive therapy
}

\author{
Sonia Bansal, Rohini Surve, Kamath Sriganesh, Jagadisha Tirthalli, Doddaballapur \\ Kumaraswamy Subbakrishna, Ganne S. Umamaheswara Rao
}

\begin{abstract}
Background: Electro-convulsive therapy $(\mathrm{ECT})$ is a safe and effective treatment for various psychiatric disorders.Among the various complications associated with ECT, acute haemodynamic responses and decrease in the oxygen saturation are the most common. The current study is designed to evaluate the relationship between the haemodynamic response and oxygen de-saturation occurring during ECT. Materials and Methods: Patients undergoing modified ECT for their psychiatric illness over a one-year period were prospectively included in this observational study. The following parameters were collected from each patient:Age, body mass index (BMI), doses of thiopentone and suxamethonium, stimulus current, ECT session number, pre-and post-ECT heart rate, systolic, diastolic and mean arterial pressure, seizure duration and pre- and post-ECT oxygen saturation. Results: The incidence of oxygen de-saturation was $27 \%$ (I39/507 sessions). The change in the heart rate and systolic blood pressure caused by ECT and the BMI of the patient were independently predictive of the change in the oxygen saturation. Conclusions: The current study identified ECT-induced acute haemodynamic changes as independent predictors of severity of oxygen de-saturation.
\end{abstract}

Key words: Acute haemodynamic changes, electro-convulsive therapy, oxygen de-saturation

\section{INTRODUCTION}

Modified electro-convulsive therapy (ECT) is currently used worldwide for the treatment for severe psychiatric illnesses like depression, drug-resistant bipolar disorder and schizophrenia. Among the various complications associated with ECT, acute haemodynamic changes including transient hypertension and tachycardia are described most commonly. ${ }^{[1,2]}$ A few studies have also documented the occurrence of oxygen de-saturation during ECT with theincidence varying from $2.5 \%-27.5 \%$. ${ }^{[3,4]}$ Currently, it remains unexplored if an association exists between the acute haemodynamic responses and the

\begin{tabular}{|l|l|}
\hline \multicolumn{2}{|c|}{ Access this article online } \\
\hline Quick Response Code: & Website: \\
\hline & www.jnaccjournal.org \\
\cline { 2 - 2 } & \\
\hline
\end{tabular}

incidence and magnitude of oxygen de-saturation. We hypothesised that patients who manifest a greater change in haemodynamic parameters also have a greater degree of oxygen de-saturation following ECT. The objective of this study is to investigate the relationship between acute systemic haemodynamic responses and oxygen de-saturation during modified ECT.

\section{MATERIALS AND METHODS}

The study was approved by the institutional ethics committee and a written informed consent was obtained from the next of the kin of the patient. All patients aged between 15 and 65 years who were scheduled for a modified ECT for their psychiatric illness were prospectively included in this observational study. Patients with a history of hypertension, recent myocardial infarction, pregnancy, intra-cranial haemorrhage and patients with baseline oxygen saturation $\left(\mathrm{SpO}_{2}\right)<92 \%$ on pulse-oximetry were excluded from the study. The clinical and demographic details like the psychiatric diagnosis, duration of illness, body mass index (BMI),

Department of Neuroanaesthesia, National Institute of Mental Health and Neurosciences, Bangalore, Karnataka, India

Address for correspondence:

Dr. Ganne S. Umamaheswara Rao, Department of Neuroanaesthesia, National Institute of Mental Health and Neurosciences, Bangalore - 560029 ,

Karnataka, India. E-mail: gsuma123@yahoo.com 
pharmacotherapy and laboratory investigations were collected for each patient.

\section{Electro-convulsive therapy protocol and anaesthetic management}

Patients undergoing ECT fasted for solids for 6-8 hours and 2 hours for clear fluids. They were evaluated prior to the ECT by the attending anaesthesiologist and the psychiatrist. A standard monitoring consisting of an electrocardiogram (ECG), non-invasive blood pressure (BP) and pulse-oximetry was established in all patients. The anaesthetic regimen consisted of administration of atropine $0.6 \mathrm{mg}$, thiopentone $3 \mathrm{mg} / \mathrm{kg}$ and suxamethonium $0.5 \mathrm{mg} / \mathrm{kg}$ for rapid muscle relaxation. During apnoea, oxygenation was maintained by administering $8 \mathrm{~L} / \mathrm{min}$ of $\mathrm{O}_{2}$ through a face mask using manual bag-mask ventilation till spontaneous respiration returned except during stimulus application. Passive oxygenation with 8 $\mathrm{L} / \mathrm{min}$ of $\mathrm{O}_{2}$ through a face mask was continued during the seizures. The ECT stimulus was delivered once the muscle fasciculations disappeared using a NIVIQURE $^{\circledR}$ (Technonivilak, Bangalore, India) ECT machine. A brief-pulse stimulus was delivered using a constant current at $800 \mathrm{~mA}$, with a frequency of 125 pulses per second $(62.5 \mathrm{~Hz})$ and a pulse width of $1.5 \mathrm{~ms}$; the duration of the train was altered to adjust the dose. The stimulus charge varied from $30 \mathrm{mC}$ to a maximum of $540 \mathrm{mC}$ and was delivered with either bi-frontal or bi-temporal electrode placement. The need for a repeat-stimulus was decided by the attending psychiatrist depending on the adequacy of seizure quality and duration. The duration of motor seizure was documented. Once the patient regained spontaneous respiration and consciousness, he was positioned in the recovery position and an oral suction performed. Later, he was shifted to the recovery room for further monitoring and observation. The data collected by an independent unbiased staff nurse included pre-ECT (before administration of anaesthesia for ECT) and post-ECT (immediately following termination of ECT-induced seizure) heart rate, systolic, diastolic and mean $\mathrm{BP}, \mathrm{SpO}_{2}, \mathrm{ECT}$ details (charge delivered, electrode placement [bi-frontal/bi-temporal], seizure duration, repeat stimulation) and anaesthetic variables (doses of thiopentone, suxamethonium and atropine and anaesthetic complications) were also collected.

\section{Statistical analysis}

A Pearson's correlation analysis was performed to examine the association between pre-and post ECT $\mathrm{SpO}_{2}$ change with the haemodynamic change, age, seizure duration, anaesthetic dose and ECT stimulus parameters. A linear regression analysis was performed to test the association between pre- and post- $\mathrm{SpO}_{2}$ difference and pre-and post-heart rate, systolic, diastolic and mean
BP differences, seizure duration and BMI. Analyses were performed using Statistical package for social sciences (SPSS) version 17. A $P<0.05$ was considered statistically significant.

\section{RESULTS}

A total number of 235 patients underwent 507 ECT sessions. The overall incidence of de-saturation was $27 \%$ (139/507 sessions). The demographic, ECT parameters and anaesthetic data are shown in Table 1. Pre-and post-ECT haemodynamic and $\mathrm{SpO}_{2}$ changes are shown in Table 2. Correlations between the study variables and the pre-and post-SpO $\mathrm{S}_{2}$ difference are shown in Table 3. When factors that were significant on univariate analysis were entered into the linear regression model, only changes in heart rate and systolic BP and BMI remained significant [Table 4].

\section{DISCUSSION}

In this study, we observed that haemodynamic changes and BMI were the factors predictive of degree of de-saturation in patients undergoing ECT. It is through the acute haemodynamic changes that the ECT-induced seizure seems to cause de-saturation along with BMI. Independent of motor convulsions, the concurrent autonomic stimulation, which occurs during ECT-induced seizures, determines the degree of de-saturation. The two factors that were significant on linear regression analysis include haemodynamic

Table 1: Demographic characteristics $(n=235)$

\begin{tabular}{lc}
\hline Parameters & Value \\
\hline Age (years) (mean $\pm \mathrm{SD})$ & $32 \pm 11$ \\
$\mathrm{BMI}\left(\mathrm{kg} / \mathrm{m}^{2}\right)($ mean $\pm \mathrm{SD})$ & $23 \pm 5$ \\
Thiopentone dose $(\mathrm{mg})($ mean $\pm \mathrm{SD})$ & $175 \pm 34$ \\
Suxamethonium dose $(\mathrm{mg})($ mean $\pm \mathrm{SD})$ & $29 \pm 9$ \\
Stimulus current $(\mathrm{mC})(\mathrm{mean} \pm \mathrm{SD})$ & $204 \pm 92$ \\
Seizure duration $(\mathrm{s})($ mean $\pm \mathrm{SD})$ & $38 \pm 15$ \\
Gender $(\mathrm{M}: \mathrm{F})$ & $126: 109$ \\
\hline
\end{tabular}

$\mathrm{SD}=$ Standard deviation, $\mathrm{BMI}=$ Body mass index,

Table 2: Pre-post-changes in the haemodynamic variables and oxygen saturation

\begin{tabular}{lccc}
\hline & Pre-ECT & Post-ECT & $\boldsymbol{P}$ value \\
\hline Heart rate (bpm) & $94 \pm 20$ & $111 \pm 20$ & $<0.001$ \\
Systolic BP (mmHg) & $115 \pm 9$ & $147 \pm 23$ & $<0.001$ \\
Diastolic BP (mmHg) & $76 \pm 8$ & $97 \pm 16$ & $<0.001$ \\
Mean BP (mmHg) & $96 \pm 7$ & $122 \pm 18$ & $<0.001$ \\
$\mathrm{SpO}_{2}(\%)$ & $98.6 \pm 1.6$ & $91 \pm 15.5$ & $<0.001$ \\
\hline
\end{tabular}

$\mathrm{ECT}=$ Electro-convulsive therapy, $\mathrm{BP}=$ Blood pressure 
Bansal, et al:: Haemodynamic changes and desaturation during ECT

Table 3: Pearson correlation analysis of pre- and post-SpO $\mathrm{P}_{2}$ change with continuous variables during ECT

\begin{tabular}{lcc}
\hline Variables & Correlation (r) & $\boldsymbol{P}$ value \\
\hline $\begin{array}{l}\text { Pre-post-heart rate } \\
\text { change (bpm) }\end{array}$ & -0.11 & 0.01 \\
Pre-post-SBP change $(\mathrm{mmHg})$ & -0.22 & $<0.001$ \\
Pre-post-DBP change $(\mathrm{mmHg})$ & -0.14 & 0.001 \\
Pre-post-MAP change $(\mathrm{mmHg})$ & -0.20 & $<0.001$ \\
Seizure duration $(\mathrm{s})$ & -0.01 & 0.8 \\
BMI $\left(\mathrm{kg} / \mathrm{m}^{2}\right)$ & -0.42 & $<0.001$ \\
\hline ECT $=$ Electro-convulsive therapy, SBP = Systolic blood pressure, \\
DBP = Diastolic blood pressure, MAP = mean arterial pressure, BMI = Body \\
mass index
\end{tabular}

Table 4: Linear regression analysis of pre- and post-oxygen saturation change during ECT

\begin{tabular}{lccccc}
\hline Parameters & B & SE & Beta & $\boldsymbol{t}$ value & $\boldsymbol{P}$ value \\
\hline HR change & -0.06 & 0.03 & -0.09 & -2.2 & 0.03 \\
SBP change & -0.12 & 0.04 & -0.18 & -3.0 & 0.003 \\
BMI & -1.25 & 0.13 & -0.40 & -9.6 & $<0.001$ \\
\hline
\end{tabular}

$\mathrm{BMI}=$ Body mass index, $\mathrm{SBP}=$ Systolic blood pressure, $\mathrm{HR}=$ Heart rate

changes and BMI, of which only haemodynamic changes are amenable for modification during ECT and thereby probably reduce the incidence of de-saturation during ECT.

Acute changes in heart rate and BP and arterial oxygen de-saturation are potential risks to patients undergoing ECT procedure. Further, occurrence of haemodynamic changes and oxygen de-saturation may lead to extended stay in the post-anaesthesia care unit with substantial utilisation of manpower and material resources. These autonomic changes may also increase the myocardial oxygen demand.

The most probable mechanisms by which acute haemodynamic changes produce oxygen de-saturation during ECT are transient neurogenic pulmonary oedema and intra-pulmonary shunting.

Neurogenic pulmonary oedema results from intense pulmonary vasoconstriction and increased left atrial pressure from systemic hypertension secondary to the sympathetic response associated with seizure, resulting in increased pulmonary hydrostatic pressure and increased permeability of pulmonary capillaries. ${ }^{[5]}$ Devinsky et al., have shown that in status epilepticus and repetitive seizures, pulmonary function remains altered even up to 72 hours. ${ }^{[6]}$ Ventilation-perfusion inequality may arise from intra-pulmonary right-to-left shunting of blood. Exercise-induced arterio-venous shunting has been demonstrated both in humans and dogs. ${ }^{[7,8]}$ ECT-induced seizure results in far greater haemodynamic change and may result in induction of these dormant shunts to produce transient de-saturation.

About 40 cases of seizure-related pulmonary oedema have been reported since the first description in $1908 .{ }^{[9]}$ It is likely that the incidence of seizure-related pulmonary capillary leak is higher than suggested by the reported cases, as cases that are mild and transient are less likely to be recognised. The alveolar infiltrates of acute neurogenic pulmonary oedema most often occur immediately after the seizure and resolve rapidly. ${ }^{[10]}$ Abdelhalim et al., reported non-seizure-related pulmonary oedema from acute hypertension following systemic absorption of topical phenylephrine. The mechanism described included increased systemic vascular resistance resulting in increase in left ventricular ejection impedance and end-diastolic volumes and pressures. ${ }^{[11]}$

ECT produces an acute dose-dependent increase in plasma norepinephrine levels and BP. ${ }^{[12]}$ Studies in acute subarachnoid haemorrhage-induced pulmonary oedema have also shown a similar increase in plasma catecholamine levels. ${ }^{[13]}$ In a study evaluating acute hypertensive pulmonary oedema, the authors observed increased afterload, reduced basal systolic function and decreased diastolic filling time. ${ }^{[14]}$ These factors might also be operational during ECT-induced seizures and acute hypertension, causing transient increase in the lung water content and contributing to de-saturation.

BMI is another important variable that affected de-saturation in our study, apart from the haemodynamic response. Takagi et al., showed a correlation between BMI and BP response to ECT. ${ }^{[15]}$ In our linear regression model, $\mathrm{BP}$ change was an independent predictor of de-saturation, which means that haemodynamic change contributes to the de-saturation, independent of other parameters.

Atropine was used as a pre-medicant in all our patients. Mayur et al. have shown that atropine contributes significantly to elevated haemodynamic response during ECT. ${ }^{[1]}$ This could have also contributed to a higher incidence and severity of de-saturation in our patients.

\section{CONCLUSION}

In this prospective observational study, the incidence of oxygen de-saturation during recovery from anaesthesia for ECT was $27 \%$. The study identified acute haemodynamic changes as independent predictors of this complication. This knowledge is likely to help in planning further investigations that attempt to decrease the incidence of de-saturation by obtunding the haemodynamic responses. 


\section{REFERENCES}

1. Mayur PM, Shree RS, Gangadhar BN, Subbukrishna DK, Janakiramaiah N, Rao GS. Atropine premedication and the cardiovascular response to electroconvulsive therapy. $\mathrm{Br} \mathrm{J}$ Anaesth 1998;81:466-7.

2. Prudic J, Sackeim HA, Decina P, Hopkins N, Ross FR, Malitz S. Acute effects of ECT on cardiovascular functioning: Relations to patient and treatment variables. Acta Psychiatr Scand 1987;75:344-51.

3. McCormick AS, Saunders DA. Oxygen saturation of patients recovering from electroconvulsive therapy. Anaesthesia 1996;51:702-4.

4. Swindells SR, Simpson KH. Oxygen saturation during electroconvulsive therapy. Br J Psychiatry 1987;50:695-7.

5. Baumann A, Audibert G, McDonnell J, Mertes PM. Neurogenic pulmonary edema. Acta Anaesthesiol Scand 2007;51:447-55.

6. Devinsky O. Effects of Seizures on Autonomic and Cardiovascular Function. Epilepsy Curr 2004;4:43-6.

7. Lovering AT, Romer LM, Haverkamp HC, Pegelow DF, Hokanson JS, Eldridge MW. Intrapulmonary shunting and pulmonary gas exchange during normoxic and hypoxic exercise in healthy humans. J Appl Physiol 2008;104:1418-25.

8. Stickland MK, Lovering AT, Eldridge MW. Exercise-induced arteriovenous intrapulmonary shunting in dogs. Am J Respir Crit Care Med 2007;176:300-5.

9. Cho I, Kai M, Ichikado K, Naitoh M, Sakata T, Suga M. A case of neurogenic pulmonary edema associated with epileptic seizure. Nihon Kokyuki Gakkai Zasshi 2002;40:817-21.
10. Fredberg U, Bøtker HE, Rømer FK. Acute neurogenic pulmonary oedema following generalized tonic clonic seizure. A case report and a review of the literature. Eur Heart J 1988;9:933-6.

11. Abdelhalim AA, Mostafa M, Abdulmomen A, Othman EA. Severe hypertension and pulmonary edema associated with systemic absorption of topical phenylephrine in a child during retinal surgery. Saudi J Anaesth 2012;6:285-8.

12. Mann JJ, Manevitz AZ, Chen JS, Johnson KS, Adelsheimer EF, Azima-Heller R, et al. Acute effects of single and repeated electroconvulsive therapy on plasma catecholamines and blood pressure in major depressive disorder. Psychiatry Res 1990;34:127-37.

13. Inamasu J, Sugimoto K, Yamada Y, Ganaha T, Ito K, Watabe T, et al. The role of catecholamines in the pathogenesis of neurogenic pulmonary edema associated with subarachnoid hemorrhage. Acta Neurochir 2012;154:2179-84.

14. Mărgulescu $\mathrm{AD}$, Rimbaş RC, Florescu $M$, Dulgheru RE, Cinteză M, Vinereanu D. Cardiac adaptation in acute hypertensive pulmonary edema. Am J Cardiol 2012;109:1472-81.

15. Takagi S, Iwata K, Nakagawa A. Relationship between body mass index and blood pressure elevation during electroconvulsive therapy. J Clin Anesth 2012;24:33-7.

How to cite this article: Bansal S, Surve R, Sriganesh K, Tirthalli J, Subbakrishna DK, Umamaheswara Rao GS. Influence of acute haemodynamic changes on the oxygen saturation during electroconvulsive therapy. J Neuroanaesthesiol Crit Care 2014;1:46-9.

Source of Support: Department Fund, Conflict of Interest: None declared.

\section{Staying in touch with the journal}

1) Table of Contents (TOC) email alert

Receive an email alert containing the TOC when a new complete issue of the journal is made available online. To register for TOC alerts go to www.jnaccjournal.org/signup.asp.

\section{2) RSS feeds}

Really Simple Syndication (RSS) helps you to get alerts on new publication right on your desktop without going to the journal's website. You need a software (e.g. RSSReader, Feed Demon, FeedReader, My Yahoo!, NewsGator and NewzCrawler) to get advantage of this tool. RSS feeds can also be read through FireFox or Microsoft Outlook 2007. Once any of these small (and mostly free) software is installed, add www.jnaccjournal.org/rssfeed.asp as one of the feeds. 